Cuadernos Filosóficos. Segunda Época, XIV, 2017 - Rosario, Argentina

La crítica de la teología como crítica de la economía

Enrique DUSSEL

\title{
LA CRÍTICA DE LA TEOLOGÍA COMO CRÍTICA DE LA ECONOMÍA
}

Prof. D. Enrique Dussel

Profesor Emérito de la UAM y SNI

(México)

Marx escribió que "la crítica de la teología [se torna] en la crítica de la política". Con completa coherencia se puede ampliar también que la crítica de la teología se torna en la crítica de la filosofía, de la economía o de la política.

Siguiendo esta indicación deseo justificar hoy, en 2017, al introducir Las metáforas teológicas de Marx, el sentido de una obra escrita hace más de treinta años. Y me situaré bajo la inspiración del mismo Marx. Para él la historia, la filosofía y la teología se relacionaban en el pensamiento crítico. Por ello escribe en un texto célebre, acerca de estos tres niveles epistemológicos, que:

"La tarea de la historia consiste en establecer el más acá [Diesseits] de la verdad, después que se ha desvanecido el más allá [Jenseits] de la verdad [...] La misión de la filosofía puesta al servicio de la historia, después de desenmascarar la forma sagrada [Heiligengestalt] de la auto alienación del ser humano, consiste en desenmascarar la auto alienación bajo sus formas profanas [unheiligen]. La crítica

\footnotetext{
* Emérito de la Universidad Autónoma Metropolitana (UAM-Iz) Investigador Nacional Emérito del Sistema Nacional de Investigadores (SNI)

1 K. Marx, Introducción a la crítica de la Filosofía del Derecho de Hegel (WEB, 1, p. 379; Obras Fundamentales, Fondo de Cultura Económica, México, t. I, p. 492).
} 
del cielo se torna de este modo en la crítica de la tierra [...], la crítica de la teología en la crítica de la política"2.

Veamos entonces la relación de estas tres epistemes: historia, filosofía y teología, quizá para escándalo de marxistas leninistas tradicionales y de cristianos antimarxistas (también de islámicos, confucianos, taoístas, budistas, etcétera).

En efecto, Marx escribió de su puño y letra que Thomas Münzer "por medio de la Biblia enfrentó al cristianismo feudal de su época con el sencillo cristianismo de los primeros siglos"3. Y continúa: "Los campesinos utilizaron este instrumento contra los príncipes, la nobleza y el clero". Ese "instrumento" es un volver a los "primeros siglos" del cristianismo, y aun antes de su institucionalización como ekklesia, y pienso que es lo que he intentado hacer toda mi vida, al comienzo de manera interrogante y entre tinieblas y luces, y posteriormente con toda claridad, ya que Marx se está refiriendo anticipadamente a algo muy semejante a lo que hoy llamamos Teología de la Liberación, en su versión más radical (como la formulación sugerida del materialismo mesiánico por Walter Benjamin, por ejemplo ${ }^{4}$ ). Deseo reflexionar sobre la cuestión, no situándome subjetivamente como el creyente de una comunidad religiosa (y sin negarlo), sino ante la objetividad socio-política, cultural y económica del mundo actual, etapa postsecularista a comienzos del siglo XXI, y como lo sugiere J. Habermas en algunas de sus últimas obras (aunque todavía eurocéntricamente). Y de una manera aún hoy provocativa, especialmente para ciertos marxistas, escribe Marx:

\footnotetext{
${ }_{2}^{2}$ Ibid., p. 379 (p. 492). Lo que se dice de la política puede decirse de la economía, el género, la raza, la estética, etcétera.

${ }^{3}$ Lucha campesina en Francia (MEW, VII, pp. 350-351; Karl Marx, Sobre la religión, ed. Hugo Assmann, Sígueme, Madrid, 1974, p. 211).

${ }^{4}$ Recuérdese la referencia de Walter Benjamin a la teología en "Sobre el concepto de la historia" en la metáfora del turco que utilizaba para jugar el ajedrez al enano escondido debajo del tablero: "Siempre debe ganar el muñeco llamado materialismo histórico, pudiendo enfrentarse con cualquiera si toma la teología a su servicio, la cual hoy en día es pequeña y fea y no debe dejarse ver en absoluto" (W. Benjamin, en Gesammelte Schriften, Suhrkamp, Frankfurt, vol. I/2, p. 693; Obras, Mabada Editores, Madrid, 2007, vol. I/2, p.305). Ciertamente esta problemática no podía ser entendida por Adorno, ni en América Latina por S. Gandler que opina que Bolívar Echeverría pensó, contra la opinión de Michel Löwy, que esta referencia teológica era secundaria y descartable, y por ello me descalifica como teólogo sin poder entender la temática en W. Benjamin.
} 
"Por lo tanto [pensaba Thomas Münzer], el cielo no es una cosa de otro mundo; hay que buscarlo en esta vida, y la tarea de los creyentes ${ }^{5}$ consiste en establecer aquí, en la tierra, ese cielo que es el Reino de Dios"

Con esta actitud objetiva, y no sólo subjetiva, deseo que inclusive el increyente crítico de izquierda al que se dirige toda mi obra, se entere de un discurso histórico teológico que destruye la justificación religiosa teológica de derecha en los sistemas dominadores, tales como el capitalismo o el liberalismo individualista político moderno que pasan por ser "cristianos". Es en este sentido que "la crítica de la teología [... se torna] en la crítica de la política", también como crítica de otros campos prácticos de la existencia humana (como la crítica de la economía, del género o del patriarcalismo, el racismo, el eurocentrismo, etc.), al desfetichizar y descolonizar esa justificación teológica de la dominación. Se pueden dar muchas otras razones para justificar ese programa crítico en otros campos, pero en esta obra me referiré principalmente al campo económico de la "crítica". Y, citando una vez más a Marx, leamos un texto un tanto inadvertido en la tradición marxista (y por supuesto cristiana), que tratamos en la exposición de esta misma obra:

“De ahí que la crítica esté en su perfecto derecho, cuando obliga al Estado [cristiano prusiano] que invoca la Biblia, a reconocer lo torcido de su conciencia [...] desde el momento en que la vileza de sus fines seculares, cuando trata de encubrirlos con [el manto de] la religión, se hallan en flagrante contradicción con la pureza de su conciencia religiosa"?.

Parece extraño que Marx hable de "pureza de su conciencia religiosa" que se expresa en un texto revelado para los cristianos, que debe interpretarse al menos como un reconocimiento positivo del "cristianismo primitivo", del que ha hablado algo antes en el mismo referido texto. ¿De qué contradicción se trata? ¿Por qué Marx quiere mostrar dicha contradicción

\footnotetext{
${ }^{5} \mathrm{Y}$ en este caso no interesa preguntarse como Porfirio Miranda si Marx era o no creyente en el cristianismo, sino si lo supo usar como crítica a una teología secular fetichizada.

${ }^{6}$ Lucha campesina en Francia (MEW, VII, p. 353; ed. Assmann, p. 213).

${ }^{7}$ Sobre la cuestión judía, I (MEW, I, pp.359-360).
} 
claramente? ¿Qué interés tiene hoy, en el presente político y económico, alcanzar claridad en esta temática?

Podemos comenzar por indicar esquemáticamente cuatro posibles contradicciones o relaciones entre el cristianismo (como religión, ética o teología) y la política, la economía, la sociología, u otros campos prácticos.

1. En una primera relación, el creyente acepta la dominación práctica (sea política, económica, social, cultural, etcétera), porque ha desconocido, olvidado o encubierto teóricamente los aspectos de su propia religión (el cristianismo primitivo) en la etapa en que se comprometió en la liberación de los pobres y oprimidos. No habría contradicción entre el cristianismo (invertido desde el siglo IV de nuestra Era al menos ${ }^{8}$ ) y la economía política burguesa (u otras dominaciones racistas, de género, culturales, etc.). El cristianismo invertido no se opone al capitalismo.

2. En una segunda posible relación, el creyente acepta la dominación práctica del capitalismo, ya que la ciencia económica naciente (por ejemplo la del calvinista presbiteriano Adam Smith) describe al mismo capitalismo como coherente con el cristianismo invertido, ocultando sus componentes de injusticia, dominación o explotación (por ejemplo, no descubriendo ni mostrando la injusticia del plusvalor logrado como parte no pagado del salario). La ciencia económica fetichizada no se opone al cristianismo.

3. En una tercera posible relación, el economista se opondría a la dominación económica del capitalismo, habiendo previamente efectuado una crítica de la economía política (por ejemplo, la realizada por Marx), mostrando la injusticia o la perversidad del capitalismo que explota al obrero, ya que acumula ganancia con el plusvalor no pagado en el salario al obrero. Esta tarea es la propia de la "crítica de la economía política", trabajo efectuado por Marx. El creyente se opondría por

\footnotetext{
${ }^{8}$ Véase el Apéndice I al final de esta obra sobre la "Descolonización epistemológica de la teología".
} 
ello mismo al capitalismo (desde argumentos racionales). Una economía crítica muestra que es contradictorio el capitalismo al auténtico cristianismo de los primeros siglos.

4. En una cuarta posible relación, el mismo creyente, redescubriendo el sentido crítico del mensaje del cristianismo (mesiánico) que se opone a las injusticias sufridas por los pobres, los débiles, lucha que emprendieron los primeros miembros de las comunidades fundadoras (sean cristiana, islámica, budista, etc.), toma conciencia de la contradicción entre religión crítica (que invierte la inversión) y el capitalismo. Esto es lo que Marx llama “crítica de la teología”. Es una crítica teológica como retorno mesiánico a los orígenes, que en América Latina ha realizado la Teología de la Liberación. Un cristianismo crítico (que invierte la inversión de la cristiandad) es contradictorio al capitalismo.

Marx se encarga de sugerir una crítica de la teología que permita a los cristianos (ahora críticos de su mismo cristianismo, y en la que consiste la contradicción 4.) situarse contradictoriamente ante el capitalismo. Para ello usó continuamente metáforas teológicas: describe al creyente el camino teórico para descubrir la contradicción de la religión cristiana crítica originaria (si es auténtica e invierte la inversión de la cristiandad) con el capitalismo, posibilidad que se cumple al desfetichizar la ciencia económica, pero sugiriendo simultáneamente una reinterpretación crítica de la teológica (que deben realizar en regla y completamente los teólogos creyentes críticos). Marx indica el método de dicha reintepretación a partir de poner a la teología "de pie", ya que andaba desde el siglo IV "de cabeza".

El cristianismo (y el islam en el Califato, etcétera) se había invertido porque el creyente aceptaba con complicidad la dominación de los sistemas vigentes (del feudalismo en el tiempo de la teología escolástica cristiana, o del mercantilismo en el del aristotelismo islámico), porque habían abandonado del mensaje cristiano el momento crítico (o mesiánico, diría W. Benjamin) del texto sagrado (en la cultura europea: la Biblia; en el caso del islámico: el Corán, etcétera), aceptación correlativa del no haberse mostrado en la naciente ciencia 
económica la injusticia del sistema capitalista. El cristianismo convertido en cristiandad medieval había efectuado una inversión del mesianismo originario; el de los califatos islámicos habían invertido el mensaje del profeta de la Meca, lo mismo aconteció en el confucianismo, en el taoísmo, en el budismo, etcétera.

De esta manera el creyente "celeste" y el dominador "terrestre" (por ejemplo, hoy el cristiano capitalista norteamericano o el islámico enriquecido financieramente con el petróleo, etc.) no tienen contradicción alguna entre su creencia y el capitalismo, porque ambos han sido invertidos, aun epistemológicamente, en la construcción ideológica de sus respectivos discursos. Uno científico, habiendo excluido de la economía su contradicción capital-trabajo como explotación del último que se manifiesta en el plusvalor por su parte ocultado; otro en la religión, habiendo también ocultado que la revelación se dirigía primeramente a los pobres y dominados y que por ello era contradictoria al capitalismo.

Por el contrario, el creyente (cristiano en este caso, pero aplicable igualmente a un confuciano, budista, taoísta, hindú o islámico), a partir del texto religioso (como Thomas Münzer entre los cristianos germánicos) puede oponerse, si retorna sus fuentes más antiguas, a muchos tipos de dominación, y en concreto al del capitalismo, del liberalismo, del racismo, del machismo, del eurocentrismo (que pasan como coherentes con las religiones invertidas, fetichizadas ellas mismas). Esta es la posición que Marx intenta exponer con claridad a los creyentes europeos y cristianos por medio de una "crítica de la teología". Desde esta luz debe también leerse el intento de mi obra histórico teológica.

Todo esto incluye también la crítica de lo que Marx denomina la fetichización o la sacralización de las "formas profanas [unheiligen]". Es decir que, contra lo que se piensa tradicionalmente (en la izquierda y en la derecha), los que se han secularizado la ciencia y las instituciones en la Edad secularista de la Ilustración eliminaron también a los "dioses terrestres", y el principal de esos dioses para Marx es el capital en cuanto tal. Lo que se ha negado o secularizado en la teología profana del "In God we trust” (que debería escribirse: "In Gold we trust", agregando una "l" [ele] entre la "o" y la "d" de God) es un dios, un fetiche inmerso en la vida cotidiana, semanal (no el Dios del sábado judío, del domingo cristiano o del viernes islámico). El gold, el capital es un dios cotidiano (fundamento ontológicoeconómico de la existencia moderna) ya que para el fundador del cristianismo (o los “cristianos primitivos", y también para el fundador del Islam) el dios "fabricado por las 
manos del ser humano", el fetiche Mamón era el Dinero (igual que para Marx). Pero en la modernidad europea secularista Mamón ha sido secularizado también y aparece simplemente como un momento económico 9 . Para Marx, por el contrario (como para los creyentes primitivos y hoy los creyentes críticos) el Dinero era un verdadero dios, pero profano, un anticristo, como lo exponemos largamente en esta obra escrita hace tiempo, pero más pertinente hoy que cuando fue redactada.

Por ejemplo, y volveremos sobre el tema posteriormente, Marx se refiere a un texto de Pablo de Tarso cuando escribe en los Grundrisse:

“[El Dinero], de su figura de esclavo [Knechtsgestalt] en que se manifiesta como simple medio de circulación, se vuelve de improviso soberano y dios (Gott) del mundo de las mercancías"10.

En la circulación el dinero tiene diversas funciones pero no su acumulación. Es un instrumento de cambio. Pero en el capital se transforma en un verdadero dios por su poder infinito de acumulación. Lo que nunca se advirtió es que Marx está haciendo referencia al autor de la Carta a los Filipenses, cuando Pablo de Tarso escribe:

"Él [Cristo] a pesar de su figura divina [Gestalt Gottes $]^{11}$, no se aferró a su categoría de Dios, sino que al contrario se alienó a sí mismo ${ }^{12}$ y tomó la figura de esclavo $[\text { Knechtsgestalt }]^{13 \%},{ }^{14}$

Es decir, el Dinero de esclavo se transformó un dios; Cristo de Dios devino esclavo. La conclusión inevitable de la crítica de la teología es que el Dinero es el anticristo para Marx,

\footnotetext{
${ }^{9}$ En una edad "postsecularista" se volverán a descubrir las divinidades ocultadas o invisibles por el secularismo.

${ }^{10}$ Grundrisse, Dietz Verlag, Berlin, 1974, p. 133 (Obras Fundamentales, t. I, p. 156).

${ }^{11}$ Adviértase el uso del concepto de "figura" [Gestalt], aplicada al "esclavo" y a "dios" (o "Dios"), palabras tomadas por Marx de la traducción alemana de Lutero del Nuevo Testamento.

${ }^{12}$ Este "se alienó a sí mismo" (entaüssen sich), a través de Hegel, se transformará en la categoría de "alienación" en Marx (¡quién diría, de origen paulino, es decir, teológico!).

${ }^{13}$ Es exactamente la expresión inequívoca en alemán de Marx, en la traducción de M. Lutero.

${ }^{14}$ Carta a los Filipenses citada, 2, 6-7.
} 
una metáfora de su crítica a la teología profana o al fetichismo encubridor, o también: crítica profana de la teología económica como la de Adam Smith ${ }^{15}$. Y parecerá todavía más extraño, a la izquierda y a la derecha, que sea el propio Engels el que escriba, refiriéndose a una crisis económica inglesa, que:

"Esta crisis es el gran combate final entre Dios y el Anticristo, como lo han llamados otros. Los capítulos decisivos son el 13 y 17 [del Apocalipsis]"16.

Esto no nos indica que Marx o Engels fueran creyentes, pero tampoco niega que los creyentes puedan adoptar las posiciones críticas de Marx ante el capitalismo. En mi caso particular fui comprendiendo, descubriendo lentamente dichas posiciones teóricas en el andar de los últimos cincuenta años. No fue una ruptura instantánea ni heredada por familia ni por maestros. Fue un lento proceso de ir abriéndome a lo más crítico del pensamiento de los siglos XIX y XX (como es el de Marx), sin negar la posibilidad del horizonte de un mundo religioso, desde dentro de una comunidad concreta histórico-cultural, como una totalidad de sentido que alienta a nuestros pueblos latinoamericanos en la vida cotidiana. Era al mismo tiempo, desde el discurso renovado de una comunidad creyente, un reinterpretar el mundo críticamente, recuperando el mensaje del "cristianismo de los primeros siglos", época extremadamente crítica donde el mesianismo (es decir, el cristianismo, ya que en griego khristianoi significa mesiánicos) fue vivido de manera ejemplar y militante ante la dominación esclavista del férreo Imperio romano, tan semejante al que nos toca sufrir en el presente siglo XXI.

Para Karl Marx entonces, la religión fundamentaba o negaba una cierta praxis. Por ejemplo, el calvinismo reformuló el cristianismo para hacerlo compatible con la ciencia económica y el mismo capitalismo que nació en su seno. No olvidar que en Escocia se practicó el presbiterianismo calvinista de John Knox, la cultura religiosa y la patria de Adam Smith. Marx critica primeramente esta inversión teológica y práctica del cristianismo (que ha dejado de ser mesiánico y crítico como en los primeros siglos, posición también asumida

\footnotetext{
${ }^{15}$ Hay reconocidos estudios sobre la teología de Adam Smith.

${ }^{16} M E W, 21$, p.11. El indica: "El cristianismo [primitivo, que es el de la Teología de la Liberación, no el de la cristiandad invertida], como todo gran movimiento revolucionario, fue establecido por las masas" (Ibid., p. 10).
} 
por Engels y Kausky). Si hay que efectuar una crítica teológica es necesario saber "entrar” en la lógica del discurso teológico (que Marx conocía muy bien, pero que el marxismo posterior ignoró completamente hasta el presente) para mostrar que la teología cristiana si es crítica no puede sino oponerse al liberalismo en política, y al capitalismo en economía. Esta es igualmente la tesis de Walter Benjamin, hoy en disputa interpretativa.

La cuestión se centra entonces en el tema del fetichismo de las "formas profanas". Primeramente, la teología moderna (española del siglo XVI) criticó a la teología medieval (que con Ginés de Sepúlveda fundamentó teológicamente el colonialismo y el capitalismo naciente). Después, el calvinismo entre otros, criticó la teología de la primera modernidad, pre-industrial, fundando así la posibilidad de una completa identificación entre cristianismo y capitalismo que desde el siglo XVIII será industrial (por el pasaje a la creación y acumulación de plusvalor relativo). Ese cristianismo escocés, calvinista, es el objeto primero de la crítica de Marx.

Por otra parte, y recientemente, los fundamentalismos (el del cristiano sectario norteamericano, el del islamista contra el Corán leído críticamente o el del sionista de derecha, en contradicción con el profetismo ético-crítico judío) son el retorno de un "dios" (o un politeísmo como diría M. Weber) que justifica y absolutiza una política, una economía, una cultura, una raza, un género, todos ellos modernos , y usa las armas en vez de argumentos razonables, comprensibles para el otro interlocutor (nadie como el fundamentalismo norteamericano utiliza el poder militar en vez de argumentos: pretende imponer la “democracia” con guerras en vez de argumentar desde la tradición del otro, por ejemplo, de los creyentes del Islam a partir del Corán ${ }^{17}$ ). Al fundamentalismo no se lo vence por las armas (y no olvidar que fue la CIA la que enseñó al fundamentalismo islamista en Afganistán a usar las armas contra la Unión Soviética, y ahora cosechan las consecuencias sobre cuyo origen nadie habla), sino con argumentos razonables y con una praxis honesta (como enseñaba Bartolomé de las Casas con respecto a la conquista desde 1514). Pero esto último no entra en el horizonte de los intereses del Imperio actual. Se utiliza la pretendida violencia irracional

\footnotetext{
${ }^{17}$ Sería mejor usar algunos millones de dólares para formar escuelas de intelectuales que hagan comprensible, “desde la tradición del Otro", lo que se pretende proponerles como mejor. Es la primera regla de la retórica. Lo que acontece es que los fundamentalismos son utilizados por el capital para aumentar su acumulación. Lo demás es hipocresía.
} 
islamista para justificar sus guerras y la explotación de otros pueblos. Por ello, la izquierda honesta debe descubrir hoy la importancia de una crítica de la teología como momento de una crítica de la política liberal y de la economía capitalista, tal como la practicó Karl Marx.

Pero todo esto no se descubrió en América Latina (ni en el transcurso de mi vida) de manera inmediata y clara, sino, por el contrario, siguiendo sinuosos caminos donde poco a poco se fue vislumbrando que, a todo lo dicho, había que sumarle la dominación colonial, la descolonización epistemológica: “Caminante no hay camino, se hace camino al andar...”.

En efecto, descubrirse la "colonialidad", el existir en un mundo colonial (más allá de M. Heidegger diríamos: "ser-en-el-mundo-colonial") y pensar la "colonialidad" de la existencia personal, familiar, comunitaria, cultural, histórica, lleva tiempo. Y más todavía hasta alcanzar la clara conciencia crítica ante el eurocentrismo y la modernidad, y con ello efectuar la tarea de una "descolonización epistemológica" de la filosofía, y ahora de la historia y de la teología. La descolonización epistemológica de la teología es entonces la última etapa (cuestión no tratada en esta obra sino en un Apéndice), pero fue desde el comienzo una compañera de viaje de la descolonización de la filosofía y de la historia.

En este comienzo del siglo XXI se nos hace posible mostrar esas etapas guardadas discretamente sin demasiada publicidad, cuando imperaba una secularización militante en la izquierda, fruto ambiguo de la Ilustración eurocéntrica. Abriéndose hoy en el horizonte un momento Postsecularista esta obra intenta mostrar una extraña anticipación temática. Mi evolución biográfica actual, en mi vejez, puede ahora volver a asumir las experiencias de mi juventud que tuvieron aún en ciertos momentos tonalidades místicas (por la práctica y lectura de autores que dieron belleza y alegría a mi entusiasmo militante y revolucionario en esa edad juvenil), y encuadrarlas dentro de horizontes abiertos por un Walter Benjamin, Jacobo Taubes o Giorgio Agamben (aunque los dos últimos inevitablemente eurocéntricos) ya anticipados por Martin Buber o por E. Levinas, pero más radicalmente por Paul Gauthier que en Nazareth (Israel) discutíamos, ambos como obreros manuales miembros de una cooperativa de palestinos que construían sus propias casas, estos temas en aquellos años del 1959-1961. 